\title{
Quando o trabalho exige lidar com a morte: o caso dos necrotomistas
}

\section{When work requires dealing with death: the case of necrotomists}

\author{
Frankleudo Luan de Lima-Silva (orcid.org/0000-0002-2663-5798)' \\ Paulo César Zambroni-de-Souza (orcid.org/0000-0002-7353-4420)2 \\ Anísio José da Silva Araújo (orcid.org/orcid.org/0000-0002-3128-3897)³ \\ Francinaldo do Monte Pinto (orcid.org/0000-0001-9597-2870) ${ }^{4}$
}

\begin{abstract}
Resumo
O presente artigo objetivou conhecer quais estratégias defensivas os necrotomistas desenvolvem para lidar com a morte em sua atividade profissional exercida no contexto do Departamento de Medicina Legal (DML), uma organização que tem a morte como fator disparador do processo de trabalho. Adotou-se como abordagem principal a Psicodinâmica do Trabalho, aliada ao conceito de trabalho sujo. Metodologicamente, combinaram-se entrevistas semiestruturadas individuais e observações da atividade na sala de necropsias. Participaram do estudo os seis necrotomistas do DML de uma capital do Nordeste brasileiro. Os resultados indicaram as seguintes estratégias defensivas: coisificação dos cadáveres, uso de brincadeiras, valorização do sentimento religioso e tentativa de neutralizar interações entre os espaços privados e os de trabalho. Constatou-se que a experiência profissional ameniza o impacto das imagens, odores e contato manual com os cadáveres. Evidenciou-se, também, que a convivência com a morte parece induzir mudanças de perspectiva positiva em relação à vida pessoal.
\end{abstract}

Palavras-chave: Psicodinâmica do trabalho. Trabalho sujo. Clínicas do trabalho. Estratégias defensivas. Necrotomistas.

\footnotetext{
Abstract

This article aimed to know which defensive strategies the necrotomists develop to deal with death in their professional activity performed in the context of the Department of Legal Medicine (DML), an organization that has death as a triggering factor of the work process. The main approach was the Psychodynamics of Work, allied to the

${ }^{1}$ Universidade Federal da Paraíba, João Pessoa, Brasil. E-mail: frankleudo.lima-silva@hotmail.com.

2 Universidade Federal da Paraíba, João Pessoa, Brasil. E-mail: paulozamsouza@yahoo.com.br.

${ }^{3}$ Universidade Federal da Paraíba, João Pessoa, Brasil. E-mail: anisiojsa@uol.com.br..

${ }^{4}$ Universidade Estadual da Paraíba, Campina Grande, Brasil. E-mail: dumontepinto@uol.com.br.
} 
concept of dirty work. Methodologically, individual semi-structured interviews and observations of the activity in the necropsy room were combined. The six necrotomists of the DML from a Brazilian Northeast capital participated in the study. The results indicated the following defensive strategies: objectification of corpses, use of jokes, appreciation of religious feeling and attempt to neutralize interactions between private and working spaces. It was found that professional experience mitigates the impact of images, odors and manual contact with the corpses. It was also evident that the living with death seems to induce positive perspective changes in relation to personal life.

Keywords: Work psychodynamics. Dirty work. Work clinics. Defensive strategies. Necrotomists.

Quais as implicações de ter a morte como uma constante em sua atividade de trabalho? O que torna exequível uma atividade que envolve cadáveres humanos violentados e os dramas que eles materializam? O que significa integrar uma organização que tem a morte como fator desencadeador do processo de trabalho? São esses os questionamentos que norteiam o presente artigo, cujo objetivo é conhecer as estratégias defensivas que os necrotomistas, do Departamento de Medicina Legal (DML) de uma capital do Nordeste brasileiro, desenvolvem para lidar com a morte no seu trabalho cotidiano.

Os necrotomistas são policiais civis que executam, sob a supervisão de peritos, como médico-legais e odonto-legais, procedimentos periciais em vítimas de mortes violentas (acidentes, homicídios, suicídios) ou em circunstâncias suspeitas, para determinar as causas, os métodos empregados e o tempo transcorrido do óbito, visando, em geral, o atendimento das solicitações judiciárias (França, 2011 ; Prestes Jr. \& Ancillotti, 2009; Silva, Souza, Araújo, \& Pinto, 2016). Os necrotomistas também são responsáveis por reconstituir, higienizar e vestir os cadáveres, entregá-los às famílias e conduzir pessoas até as câmaras frias para o reconhecimento de cadáveres. Todas essas situações colocam tais trabalhadores em contato com a realidade da morte violenta (Cavedon \& Amador, 2012), que envolve, muitas vezes, cadáveres bastante danificados, mutilados, carbonizados ou em estado de decomposição.

Durante as necropsias, são os necrotomistas quem fornecem as condições para que os peritos visualizem as lesões e cavidades corporais e as descrevam de forma detalhada, para que tirem as conclusões que serão apresentadas no laudo pericial. Exercem suas atividades basicamente na sala de necropsias dos institutos de medicina legal, salvo quando são necessárias necropsias pós-exumações, ocasiões em que eles se deslocam para os 
cemitérios (Prestes Jr. \& Ancillotti, 2009). Sem o trabalho desses profissionais, portanto, os processos de investigação de muitos crimes não poderiam ser realizados.

Nos casos de homicídio, por exemplo, a morte provoca impactos nas vidas dos familiares (Costa, Njaine, \& Schnenker, 2017), que buscam o julgamento dos culpados para aliviarem-se parcialmente da dor, o que não seria possível sem a atividade do necrotomista. Além disso, a celeridade na liberação do corpo para que se inicie o velório e o sepultamento é elemento central para amenizar o sofrimento dos entes enlutados, o que torna o discreto trabalho desses profissionais ainda mais imprescindível. Durante a liberação dos corpos, os necrotomistas, por vezes, têm contato com os parentes das vítimas, os quais, ainda que extraordinariamente, expressam seus agradecimentos pelos serviços prestados (Silva, 2014).

Apesar da importância social, o trabalho desse profissional é cercado de grande estigma, sendo muitas vezes tratado de "necrófilo a canibal" (Silva et al., 2016, p. 135), faltando a ele o reconhecimento social à altura da importância que possui. Tal atividade pode ser enquadrada no universo do "trabalho sujo" (dirty work), conceito proposto pelo sociólogo estadunidense Everett Hughes (1962), guiado por uma reflexão crítica sobre os impactos da divisão do trabalho nos campos moral e psicológico, na qual acentua diferenças entre profissões valorizadas e profissões sem visibilidade, ou estigmatizadas (Lhuilier, 2013). No rol das atividades tipificadas como trabalho sujo estão aquelas que lidam com objetos cujos aspectos físicos, morais ou sociais remetem à tabus ou condições degradantes, repulsivas e indesejáveis. Tratam-se de atividades que, a despeito de serem necessárias e benéficas à coletividade, sustentam marcas de desprestígio e invisibilidade sociais, sendo, em geral, estigmatizadas (Bendassolli \& Da Rocha Falcão, 2013; Butler, Chillas, \& Muhr, 2012; Hughes, 1962). Hughes (1962) acrescenta que a mesma sociedade que destina o trabalho sujo a determinados grupos de profissionais exerce sobre eles forte estigmatização. Ou seja, a mesma sociedade que demanda trabalhos sujos priva aqueles que os realizam do status social que ela atribui a outras ocupações profissionais (Barros \& Silva, 2004; Emerson \& Pollner, 1976; Hughes, 1962).

No conjunto das atividades categorizadas como trabalho sujo, enfatiza-se, neste artigo, a atividade dos necrotomistas do DML, organização que serviu como campo de investigação. As pesquisas que enfocam as organizações de trabalho cuja rotina abrange a 
presença da morte concentram-se, via de regra, na área da saúde (Almeida, 2005; Kessler, Heron, \& Dopson, 2012; Oliveira, Schirmbeck, \& Lunardi, 2013; Scarton et al., 2013; Silva, Valença, \&, Germano, 2010); contudo, são escassas publicações científicas na área pericial, notadamente envolvendo os profissionais necrotomistas (Barros \& Silva, 2004; Silva, Zambroni-de-Souza, \& Araújo, 2014; Messias, 2017).

Em tempo, estudos evidenciam a existência de defesas psíquicas comuns entre profissionais que lidam com os mortos, como, por exemplo, a de não considerar os corpos com os quais trabalham como humanos, já que tal reconhecimento pode tornar a atividade insuportável (Aldé, 2003; Avellar, Iglesias, \& Valverde, 2007; Barros \& Silva, 2004; Souza \& Boemer, 1998). Tais defesas (Dejours, 2015a; Molinier, 2008) permitem aos trabalhadores resistirem às pressões do trabalho, amortizando-as e contribuindo para a manutenção do equilíbrio (dinâmico) psíquico.

A Psicodinâmica do Trabalho (PDT) tem seu foco nas "pesquisas que vão do sofrimento ao prazer no trabalho, das patologias mentais à realização de si mesmo através do trabalho" (Dejours, 2013, p. 10). Ela tem suas raízes na Psicopatologia do Trabalho (PPT) francesa, que, embora a expressão tenha sido usada pela primeira vez apenas em 1952, por Sivadon, surgiu no final da primeira metade do século XX (Dejours, 2009, 2013, 2015b; Dejours \& Gernet, 2012; Zambroni-de-Souza \& Athayde, 2006). Além da herança recebida pela PPT, a PDT recebeu forte influência da Ergonomia da Atividade (em especial com Alain Wisner), da Psicossomática (sobretudo com Pierre Marty), da Psicanálise (especialmente a partir de Jean Laplanche), da Sociologia Compreensiva (com a influência decisiva de Paul Ladrière), da Sociologia das Relações de Sociais de Sexo (provocada por Danièle Kergoat e Helena Hirata), dentre outros. A PDT tem em Christophe Dejours seu fundador e principal referência.

Segundo a PDT, o trabalho se apresenta como central para a subjetividade e para a busca da saúde. A disciplina entende trabalho como sendo "a atividade coordenada, desenvolvida por homens e mulheres, para enfrentar aquilo que, em uma tarefa utilitária, não pode ser obtido pela execução estrita da organização prescrita" (Dejours, 2014a, p. 41). Essa definição aponta para o essencial: o enfrentamento por homens e mulheres (marcando assim a urgência de evidenciar a divisão sexual do trabalho) da defasagem, descoberta pela 
ergonomia da atividade (Wisner, 1984) entre trabalho prescrito e real e que se manifesta na busca de soluções para os impasses do trabalho sob o comando da inteligência da prática. Como a própria denominação já sinaliza, essa inteligência prática se desenvolve no enfrentamento de situações concretas de trabalho, especialmente sob a forma de imprevistos (Wisner, 1984).

A PDT advoga que a clínica das defesas constitui um meio privilegiado de desvendamento das situações de trabalho, precisamente porque lança luzes sobre as fontes de sofrimento e medo no trabalho e sobre o modo como os trabalhadores lidam com isso na tentativa de conjurar a possibilidade do adoecimento psíquico. Dejours (2016a) assinala que a descoberta das defesas no trabalho representou um avanço importante, já que se passou a investigar também os recursos psíquicos mobilizados por aqueles que conseguem resistir aos efeitos nocivos provocados pelos constrangimentos laborais.

Para Dejours (2016a), os humanos não são passivos frente aos constrangimentos organizacionais e exercem sua autonomia construindo estratégias defensivas, individuais ou coletivas, enquanto modos de lidar com situações concretas. Essas defesas cumprem a função de atenuar o sofrimento, sem, todavia, proporcionar a cura ou a transformação. Quando utilizadas com parcimônia, protegem o aparelho psíquico dos riscos de descompensação, já que "sua função primordial é de resistir psiquicamente à agressão que constituem certas organizações do trabalho" (Dejours, 1988, p. 14). Porém, quando transformadas em finalidade, podem desempenhar a função de freio à reapropriação, emancipação e transformação. Uma clínica das defesas pode revelar-se de muita utilidade para enxergar as fontes de incômodo no trabalho e as estratégias defensivas mobilizadas no seu enfrentamento, que podem colaborar para a estabilização de uma situação de trabalho nociva (Dejours, 2015b). Essa é a razão pela qual se privilegia, neste artigo, um exame das estratégias defensivas acionadas pelos necrotomistas para tornar o seu trabalho exequível.

\section{Método}

A pesquisa foi realizada no Departamento de Medicina Legal (DML) do Instituto de Polícia Científica (IPC) de uma capital do Nordeste brasileiro. Participaram deste estudo os 
seis necrotomistas dessa organização, sendo todos do sexo masculino, com idades entre 32 a 48 anos e tempo de trabalho oscilando entre quatro e 23 anos.

Para a coleta de dados, foram utilizadas entrevistas semiestruturadas individuais e quatro observações das atividades de trabalho dos necrotomistas na sala de necropsias. A partir das entrevistas, buscou-se evidenciar o cotidiano de trabalho dos necrotomistas, os imprevistos enfrentados, as estratégias desenvolvidas para lidar com a morte no trabalho, a que condições de trabalho estão submetidos, como enfrentam os estigmas que repousam sobre sua atividade profissional, se consideram (ou não) o reconhecimento de seu trabalho, o que os faz sofrer e ter prazer no trabalho. Por sua vez, as observações procuraram verificar in loco como se efetiva a atividade de trabalho dos necrotomistas, atentando para ações, gestos, posturas, comunicações (notadamente sob a forma de códigos), assim como para imprevistos que surgem e para as regulações desencadeadas.

Após aval de um comitê de ética em pesquisa e autorização da gerência do DML, um dos membros do grupo de pesquisadores contatou e apresentou a cada necrotomista a proposta do estudo. Uma vez consentida a participação, foram agendados dia e hora para as entrevistas individuais, as quais ocorreram durante os plantões dos participantes, precisamente no período noturno. No decorrer dessa etapa, solicitou-se a cada um dos participantes a permissão para o registro de observações sobre as atividades desenvolvidas durante a jornada de trabalho.

As observações, que ocorreram após todos os participantes serem entrevistados, foram efetuadas na sala de necropsias, mediante autorização dos necrotomistas, da gerência do DML e dos peritos de plantão. Em datas e com equipes distintas, realizamos quatro observações durante o turno da manhã, de $8 \mathrm{~h}$ às $12 \mathrm{~h}$, quando, via de regra, o movimento na sala é mais intenso. Cada equipe plantonista é formada por dois peritos médico-legais, dois peritos odonto-legais e dois necrotomistas. Mesmo trabalhando em equipe, o foco das observações incidiu na atividade dos necrotomistas e nas interações que eles mantinham com os outros participantes da situação de trabalho. Após cada observação, o pesquisador anotava em um diário de campo as impressões que aquela observação havia produzido. Os materiais advindos das observações foram cotejados com os das entrevistas na produção das análises da seguinte forma: na medida em que os pesquisadores procediam a análise de 
conteúdo, descrita a seguir, procuravam consultar o diário de campo para tentar compreender se a fala dos entrevistados produzia eco com o que fora observado.

Para análise dos dados, recorreu-se à análise de conteúdo temática, proposta por Laville e Dionne (1997), que se estruturou nas seguintes etapas procedimentais: inicialmente, foram organizados os materiais produzidos através da transcrição integral das entrevistas; a seguir, procedeu-se a um estudo minucioso do conteúdo, a fim de buscar as ideias ali presentes; na análise propriamente dita, codificou-se todo o material por categorias, tornando possível captar o conteúdo, que, em função de suas semelhanças, foi agrupado como unidades de sentido. Dessa forma, foi possível recortar o conteúdo a partir de temas, dentre os quais se encontra abordado, neste artigo, o "Lidar com a morte".

Cumpre ressaltar que, a fim de evitar viés, a análise das respostas foi conduzida mediante avaliação de três juízes (pesquisadores no campo da psicologia do trabalho). Primeiramente, cada juiz recebeu o material integralmente transcrito e o categorizou, segundo os pressupostos teóricos da PDT. Concluídas as categorizações individuais, as respostas foram, por fim, analisadas coletivamente.

\section{Resultados e discussão}

\section{O lidar com a morte e as estratégias defensivas mobilizadas pelos necrotomistas}

A partir dos dados empíricos, verificou-se que os necrotomistas estão expostos a dificuldades cotidianas de lidar com mortes violentas e com o sofrimento dos familiares das vítimas. Isso constitui uma situação potencialmente desestabilizante, frente a qual esses profissionais lançam mão de estratégias defensivas, individual e coletivamente elaboradas (Dejours, 2015a, 2016a). Essas estratégias representam operações que modificam a maneira como os trabalhadores percebem sua realidade, mas não a realidade propriamente dita (Dejours, 2012, 2016a), pois operam apenas na ordem do domínio simbólico do perigo (Molinier, 2008).

Coisificar os cadáveres, isto é, tratá-los como objetos, destituídos de seus dramas e de suas histórias, funciona como uma espécie de blindagem emocional, da qual muitas 
vezes não se dão conta, mas que puderam verbalizar a partir do que foi provocado pelo pesquisador durante as entrevistas. Não se trata, como os participantes fizeram questão de enfatizar, de uma mera insensibilidade à dor alheia, mas de um recurso protetivo e necessário, capaz de evitar descompensações psíquicas (Aldé, 2003; Barros \& Silva, 2004). O relato abaixo considera tal aspecto:

A gente sabe que o cadáver que está ali, a pessoa que outrora teve vida, ela tem um pai, uma mãe, um irmão, uma esposa, um filho, tem uma história e essas pessoas estão chorando por ela. A gente tem que respeitar, mas não quer dizer que a gente tenha que entrar na dor deles. Então, a gente procura o mínimo possível se envolver com a história. A gente convive com o lamento, a penúria, a dor. Se a gente se envolver com essas coisas, a gente nem consegue trabalhar. A verdade é essa! As pessoas classificam a gente como pessoas frias, mas é uma defesa, entendeu? (Participante 4)

Para alguns necrotomistas, como foi possível evidenciar nas observações, olhar o rosto dos cadáveres é um ato particularmente incômodo, que pode comprometer o distanciamento afetivo que eles tanto prezam. Esse tipo de comportamento também foi verificado em estudo desenvolvido por Barros e Silva (2004). Ao realizarem a necropsia, os necrotomistas evitam fixar seu olhar em detalhes que julgam desnecessários à realização de sua tarefa. O cadáver, assim, fica reduzido a órgãos e lesões.

Você nem olha mais para a face do cadáver, só quando é necessário. Por exemplo, para verificar se há escoriações na região zigomática, se há fratura de mandíbula, se há lesão no globo ocular. Mesmo assim, é um olhar técnico. Você não olha para a face do cadáver, pensando: "Era uma pessoa em vida, que devia ter família, coitado dele!" É uma questão de higiene mental, se você se compadecer com cada caso que seja, você não trabalha. (Participante 1)

Ainda a respeito da objetificação dos cadáveres necropsiados e da proteção emocional, um dos participantes forneceu um relato emblemático da eficácia das estratégias defensivas. Mesmo realizando a necropsia de amigos ou conhecidos, esses só tiveram suas identidades reconhecidas após a entrega do corpo à família. 
Já aconteceu três vezes comigo, eu fiz três necropsias de três conhecidos (em tempos diferentes) e não os conheci, e era gente próxima mesmo. Como eu trabalhava em uma cidade diferente da que eu nasci, eu nunca imaginei que pudesse encontrar alguém conhecido, até pela distância. Isso aconteceu três vezes. Eu fiz a necropsia e quando cheguei lá fora, um bocado de gente conhecida, e eu: "O que vocês tão fazendo aqui?". "É fulano que está aí." "Tá não, rapaz." "Tá, ele já vai ser liberado agora". Então, aconteceu por três vezes, e eu não associei o corpo à pessoa. (Participante 2)

O próprio ritmo de trabalho, intensificado em função do aumento contínuo do número de mortes violentas (Oliveira, 2015), parece concorrer para o não envolvimento dos necrotomistas com as situações dramáticas que diariamente se sucedem no seu espaço de trabalho. A postura de se concentrar racionalmente no trabalho para poder operacionalizar aquilo que the cabe tecnicamente, além de evidenciar a necessidade de controle do medo e da angústia, eleva a produtividade dos profissionais, mesmo que signifique um aumento na carga física e psíquica do trabalho (Dejours, 2012, 2016a, 2016b). Um dos necrotomistas assim se posicionou:

Toda a vida, o número de profissionais foi muito inferior ao necessário e a gente não tem tempo de se envolver com essas coisas. É preciso dar dinâmica pra que você possa fechar o dia concluindo a rotina. Então, você já deixa de pensar no cansaço, no estresse. O que é que você quer? Terminar o exame, liberar (porque a família está esperando), entregar. Vem a fome, você só se lembra que tem que ceiar, que se alimentar e logo voltar pro trabalho. Isso começa a 'desligar' você dessa relação. É um dispositivo tão automático que você começa o exame e só quando você vai costurando, reconstituindo é que o corpo humano começa a tomar forma novamente e aí que cai a ficha. (Participante 2)

Contudo, existe um diferencial na necropsia de crianças, principalmente daquelas vítimas de violência sexual, que resiste à pretensa impermeabilidade emocional. A fragilidade da criança aparece como elemento que instaura uma maior perplexidade em face do crime, como revela o Participante 1: "Recém-nascidos, natimortos ou crianças com a vida 
começando: dois, três, quatro anos, vítimas de morte violenta. Nesses casos, eu me sinto especialmente tocado".

Essa sensibilidade se revela mais acentuada quando se trata de caso de abuso sexual: Com criança é complicado. Como eu disse a você, a gente faz o possível para não se envolver, mas tem casos que não tem como, principalmente quando é criança que sofre abuso. É complicado! É complicado porque a necropsia é muito regida pela emoção. A gente vai fazendo a necropsia e dizendo: "Olhe, doutor! Veja o que o cara fez!". Agora, depende também das circunstâncias, porque tem criança que morre de acidente ou coisa do tipo, mas quando tem abuso, tem maus tratos... Aff! A gente já passou por cada coisa aqui! Aí a gente sente, a gente sente de verdade. (Participante 4)

Mesmo quando não se trata de situações de abuso sexual, como crimes e acidentes envolvendo crianças, há um sofrimento característico se o profissional possui filhos ou netos na idade da criança vitimada (Barros \& Silva, 2004; Cavedon, 2009; Gernet, 2009). O relato de um dos necrotomistas torna explícita tal relação: "Por exemplo, eu tenho uma filha de nove anos, quando o corpo da criança se assemelha ao da minha menina, dá um choque ainda maior" (Participante 6).

A tentativa do não envolvimento com as tragédias materializadas pelas mortes também se apresenta na atividade de conduzir os familiares para o reconhecimento de cadáveres nas câmaras frias. Os necrotomistas seguem regras não formalizadas, mas que se constituem em verdadeiras regras de ofício (Cru, 1987), que parecem funcionar para evitar o envolvimento emocional; ultrapassá-las pode despertar vivências de ansiedade. Uma primeira regra informa que eles devem recrutar, dentre os familiares do necropsiado, aquele que aparenta um maior equilíbrio emocional e, por suposto, está mais habilitado fazer o reconhecimento do cadáver.

Embora essa seja uma recomendação geral da organização do trabalho, o critério de percepção é fundamentalmente empírico, singularizado, forjado na prática. Essa recomendação reflete, ainda, uma preocupação com a reação emocional do familiar eventualmente impactado pela infeliz constatação. De acordo com os participantes, a maior parte dos reconhecimentos de cadáveres tem sido feita através de fotografias periciais, as 
quais têm se mostrado um recurso menos perturbador para os familiares. Os necrotomistas também tentam desviar-se da carga emocional dos momentos de reconhecimento, focando na burocratização do processo de liberação do corpo.

Verificou-se que a relação do trabalho com a família também suscita a mobilização de condutas defensivas por parte dos necrotomistas. Destaca-se, por exemplo, o fato de alguns dos profissionais evitarem falar do trabalho no ambiente familiar, o que parece funcionar como vetor de preservação da sua saúde mental (Aldé, 2003; Dejours, 2016a), na medida em que protegem sua vida pessoal e tempo livre de serem invadidos pela profissão.

Em assunto de trabalho eu não toco em casa. Minha mulher não puxa esse papo. Minha filha não tem muita curiosidade no meu trabalho, se ela tivesse uma curiosidade natural, eu comentaria, mas isso não acontece. Além disso, elas sabem que eu não gosto de falar do meu trabalho, então elas respeitam. Então, eu sou necrotomista do portão pra cá. Não sei se é uma válvula de escape ou é mecanismo de defesa, mas meu trabalho fica do portão pra cá. (Participante 5)

Dejours (2014b) afirma que o cônjuge e toda a família participam da manutenção das defesas psíquicas daquele que trabalha. Há uma espécie de cooperação psicológica intrafamiliar para permitir ao sujeito que trabalha conservar sua saúde mental. Aldé (2003) e Cavedon e Amador (2012) evidenciaram esse aspecto nas pesquisas envolvendo trabalhadores de departamentos de medicina-legal e de criminalística. Podemos considerar que a situação revelada no depoimento do Participante 5 seja apenas parcialmente possível, pois o trabalho não deixa de invadir outras esferas da vida do trabalhador, mesmo que sob a forma de enigma, ou seja, daquilo que não se pode falar no ambiente familiar. Em outros termos, o trabalho se faz presente na vida privada a partir do silêncio sobre o que nele ocorre. Ainda assim, o trabalho e suas preocupações acompanham os trabalhadores em seu tempo livre (Dejours, 2016a), pois o funcionamento psíquico não é divisível, não sendo possível ao necrotomista deixá-lo no portão ou na sala de necropsias juntamente com os instrumentos de trabalho.

A adesão à religião e ao consumo de álcool, mesmo que essa segunda situação não tenha sido tão recorrente como aparece em outras pesquisas (Aldé, 2003; Halpern, Ferreira, \& Silva Filho, 2008; Lima, 2010; Seligmann-Silva, 2011), podem se configurar como 
mecanismos defensivos individuais para alguns necrotomistas. Os depoimentos a seguir apontam nessa direção:

Eu sou católico, não sou praticante, mas faço minha oração quando chego, às $18 \mathrm{~h}$ rezo também e quando vou dormir, ou seja, eu tento me proteger religiosamente, porque é uma coisa que eu acredito. (Participante 4)

Mas eu acho que essa questão da bebida age como o bálsamo para o meu trabalho, um bálsamo meio perigoso. Funciona às vezes, funciona no dia, mas no dia seguinte a "deprê" vem dobrada. (Participante 5)

Uma estratégia que é coletivamente partilhada por todos os necrotomistas do DML é o uso de distrações durante as necropsias. Observamos o uso de recursos lúdicos envolvendo a utilização de apelidos, comentários jocosos sobre os relacionamentos amorosos de alguns profissionais; chacotas com um necrotomista que havia adotado uma nova dieta alimentar etc. Alguns necrotomistas cantavam e cantarolavam, outros conversavam sobre comida. É comum que a estratégia coletiva de defesa se manifeste ao falarem eufemisticamente do conteúdo do seu trabalho, quando, por exemplo, em tom de brincadeira um necrotomista disparou: "Vou falar com o diretor para disponibilizar uma câmara dessas para a gente colocar umas Skols [marca de cerveja brasileira] nos finais de semana" (Participante 5).

Ademais, a prática de certas brincadeiras, utilização de apelidos e outras formas de descontração tem função expressiva nas relações de trabalho, comumente verificada em situações de aparente tetricidade, a fim de tornar o trabalho mais leve e suportável (Dejours, 2001, 2015b). Usa-se o humor para disfarçar a dor (Cavedon, 2009). No caso dos necrotomistas, as histórias são muitas, e o detalhe que faz rir, embora possa parecer pequeno em meio às tragédias, apresenta-se como indicativo de defesa, uma forma de distração ao que faz sofrer.

Embora os necrotomistas tentem pensar em seu trabalho como algo habitual ("Nosso trabalho é um trabalho científico como qualquer outro" - Participante 4), reconhecem muitas vezes que não é exatamente assim, posto que exige o apelo a determinados recursos que os ajudem a geri-lo no dia a dia. Alguns relatos são ilustrativos nesse sentido: "Tem que ter essas brincadeiras, senão a gente não aguenta isso aqui" (Participante 3). 
[Brincar] É uma forma natural, depois de 20 anos, de driblar o clima, há uma certa tensão, já que a gente lida com violência, com mortes... É, anestesiar o trauma da situação... Isso acontece, principalmente, com os mais antigos. É como se, com o tempo, a gente fosse aprendendo que o trabalho pode ser menos pesado quando tem um pouco de humor inserido. (Participante 2)

A utilização de tais recursos lúdicos não constitui uma expressão de imprudência ou descuido com o trabalho. Ao contrário, podem traduzi-lo como um artifício, muitas vezes imprescindível, presente em diversas atividades laborais (Aldé, 2003; Cavedon \& Amador, 2012; Silva, Zambroni-de-Souza, \& Araújo, 2014; Mattos, 2012). Ressalta-se, ainda, que as brincadeiras e demais modos de distração podem funcionar como defesas que afastam a racionalidade do cotidiano (no trabalho) e permitem que se continue trabalhando. Só são possíveis entre colegas que possuem afinidades e em um ambiente que os acolha, o que aponta para uma dimensão coletiva e regras de ofício também presentes nessas ações (Cru, 1987).

\section{"Não é exatamente um boticário": as experiências sensoriais vivenciadas nessa atividade}

Outro aspecto susceptível de análise, arrolado pelas entrevistas e observações e também levantado por Barros e Silva (2004) em pesquisa com profissionais do DML de Belo Horizonte, Minas Gerais, refere-se às experiências sensoriais que os necrotomistas vivenciam no seu trabalho. Alguns participantes relembraram o início da sua atuação no DML como sendo um período de muitas dificuldades de lidar com as imagens, odores e ao contato manual com os cadáveres, ressaltando a dificuldade de lidar com os rostos, já que ainda não participavam da estratégia defensiva coletiva de evitar encará-los.

No primeiro mês, as imagens ficam muito vivas na mente. Os rostos. Os primeiros rostos você não esquece. O cheiro! Dá a impressão que você fica impregnado com o cheiro, mas é só impressão, é só uma ilusão olfativa, mas dá a impressão que o cheiro fica nos cílios das suas narinas. Então as imagens se repetem, seja na vigília ou durante os sonhos (porque você sonha também). Tem o cheiro e a dificuldade em se alimentar, especialmente no que diz respeito à carne, principalmente devido à 
semelhança entre a carne humana e a carne bovina ou suína. É impossível não associar as duas carnes. Outros alimentos como os grãos de feijão, os grãos de arroz, o macarrão. Por quê? Porque, em muitos casos, chegam corpos com conteúdo alimentar saindo pela boca, e você ver o alimento perfeitamente, ainda não totalmente digerido. Essa imagem fica gravada na sua mente e na hora da refeição você lembra. Você está vendo o grão de feijão no seu prato e se lembra do grão de feijão que estava saindo do orifício oral do cadáver. O tato também é marcante, porque os cadáveres estão frios ou gelados. Mas assim, isso é só no começo. Com o tempo, esse impacto, essas impressões vão diminuindo e vai se tornando automático. Você não reflete mais sobre o ato, você apenas executa o ato. (Participante 1)

A experiência no trabalho tende a amenizar as sensações experimentadas no início das atividades e constituir apenas uma lembrança, mas o episódio relatado revela a tensão vivenciada pelo então novato. Em relação aos cadáveres em decomposição, a experiência sensorial é ainda mais marcante e difícil (Barros \& Silva, 2004; Cavedon \& Amador, 2012), em função do forte e impregnante odor fétido, das imagens de vermes e insetos necrófagos que pululam nos cadáveres e da experiência tátil com os tecidos orgânicos rúpteis e amolecidos. Trabalhar com esse objeto supõe uma incorporação pelo corpo, uma corpropriação (Dejours, 2016c) para que os odores desagradáveis possam ser sentidos com menos intensidade. Trata-se, portanto de uma diminuição da capacidade olfativa a fim de tornar o trabalho e a vida fora do trabalho suportáveis. Para lidar com esses cadáveres, também utilizam a estratégia defensiva coletiva da eufemização, dando-Ihes o nome de "podrão" em suas práticas linguageiras (Cru, 1987), como presente no discurso de um necrotomista:

O primeiro cadáver em decomposição, aqui alguns costumam chamar de "podrão", é uma coisa muito forte. É uma cena deplorável. Era um rapaz. Eu me lembro que o cheiro atravessou as luvas, as roupas. Eu tive que usar álcool, sabão em pó, água sanitária nas mãos. O mau cheiro gruda em você e você tem a impressão que não larga mais. Você tem que meter a mão num monte de tapurus [vermes necrófagos] e 
nos fluidos apodrecidos. Não é fácil, não. Não é exatamente um boticário. (Participante 5)

Ocorre que mesmo utilizando os equipamentos de proteção individual (EPI) necessários (luvas, jalecos, aventais, máscaras, botas emborrachadas), tanto os pulmões quanto a pele dos profissionais parecem absorver as moléculas odorantes exaladas pelos cadáveres em putrefação. Assim, para os necrotomistas, torna-se um incômodo sentirem o cheiro pútrido no próprio corpo, mesmo depois que deixam o ambiente de trabalho, e um constrangimento ao perceberem que também outros o sentem.

\section{Sobre a positividade do trabalho dos necrotomistas}

Examinados alguns dos aspectos do cotidiano de trabalho dos necrotomistas que apontam para situações com conotações negativas, cabe mencionar algumas repercussões consideradas positivas desse trabalho. A convivência com a morte parece induzir mudanças de perspectivas frente à vida (Aldé, 2003; Kessler et al., 2012; Oliveira et al., 2013) que, se não tornam o trabalho em si mais agradável, auxiliam os necrotomistas a adotarem atitudes que os ajudam a valorizar e aproveitar melhor a vida.

Cavedon e Amador (2012) observam que tomar consciência da fragilidade da vida tem seu preço: "Tanto pode imobilizar diante da certeza do fim, quanto pode nos encher de possibilidades de vida, enquanto ela houver" (p. 197). Nesse sentido, alguns necrotomistas mencionaram que, após ingressarem no DML, mudaram de perspectiva diante da vida, reformulando seus valores. "O lado positivo desse meu trabalho é que o camarada fica mais consciente da fragilidade humana" (Participante 5). "Passei a ver as pessoas acima dos jogos de vaidade, de orgulho e de valorização das aparências. Eu já vi, aqui nessa mesa, mulheres belíssimas, crianças lindas, pessoas na flor da idade, que se acabaram aqui" (Participante 1).

Eu já parei pra pensar e já reformulei muitos valores que eu tive. Quando eu comecei a trabalhar eu não tinha muita noção, mas a gente vai amadurecendo e as coisas vão se clareando. Hoje, eu mudei muito meus valores, minhas expectativas, meus relacionamentos em relação à iminência da morte. O mesmo fenômeno da morte, para mim, por tudo o que eu já vivi, eu encaro a morte como algo que faz com que 
eu revalorize a minha vida, entendeu? O que eu puder fazer para consertar relacionamentos, para viver a minha vida como eu acho que deve ser vivida eu faço. Você já viu um cadáver em decomposição? É um estado lastimável. Ele é 20\% pele e 80\% verme. Quando você olha isso ali, você pensa: "Eu vou passar por isso". Então, diante dessa constatação, você se pergunta: "Diante desse fenômeno, qual é a minha atitude em relação à vida?" Eu vou beber, vou pular carnaval, vou viver minha vida intensamente ou, então, eu vou tentar valorizar minha família, minhas relações afetivas. As respostas, cada um vai dar à sua maneira. (Participante 6)

Corpos violentados, histórias interrompidas, aflição dos familiares das vítimas são exemplos de situações desse cotidiano de trabalho do necrotomista, frente as quais ele precisa negociar, já que a relação da organização do trabalho com o psiquismo não é um bloco monolítico (Dejours, 2016a), sendo necessário estabelecer uma relação dinâmica da qual o sujeito possa retirar elementos positivos para sua vida e sua saúde. Essa relação incita a criação de novas formas de vivenciar o mundo do trabalho e de recriação desses profissionais enquanto sujeitos (Aldé, 2003; Cavedon \& Amador, 2012), já que o trabalho nunca é neutro com relação à saúde e à subjetividade (Dejours, 2015b).

Por fim, a utilidade do trabalho dos necrotomistas na elucidação dos fatos também serve para dar sentido (Dejours, 1994) positivo à sua atividade e conferir a eles realização profissional, embora, muitas vezes, não tenham acesso ao desdobramento final de suas contribuições no desfecho das investigações policiais e das sentenças judiciárias.

\section{Considerações finais}

As reflexões aqui desenvolvidas evidenciam que a relação dos necrotomistas com seu objeto de trabalho é mediada por estratégias defensivas individuais e coletivas, sem as quais as vivências do sofrimento não seriam suportáveis. O sofrimento decorre, dentre outros aspectos, dos dramas que envolvem entrar em contato com corpos dilacerados, em estado de putrefação, e com familiares desesperados. Para além de mecanismos de defesa, como uso de álcool, confiança em alguma religião e tentativa de neutralizar interinfluências entre os espaços de trabalho e o privado, verificou-se que os necrotomistas recorrem a 
estratégias defensivas construídas, organizadas e gerenciadas coletivamente, tais como: coisificação dos cadáveres e uso de diversas formas de distração.

O recurso à defesa é o caminho esperado de quem enfrenta situações desestabilizantes e, quando utilizado parcimoniosamente, cumpre uma função protetora importante. No caso aqui estudado, a própria natureza do trabalho parece demandar a utilização de estratégias defensivas como forma de torná-lo exequível. A defesa é, nesse sentido, consubstancial ao trabalho, em especial no caso dos necrotomistas. Como evidenciado pela literatura apresentada neste artigo, várias estratégias defensivas aqui elencadas são utilizadas por necrotomistas de outros DML e por outras categorias profissionais que lidam permanentemente com a morte.

Compreende-se que as sensações experimentadas, sobretudo as que envolvem necropsias de crianças e cadáveres em decomposição, são bastante desconfortáveis e marcantes para esses profissionais, especialmente no início da carreira. Segundo os necrotomistas, as sensações, contudo, são passíveis de apropriação/corpropriação (Dejours, 2009) com a experiência de trabalho no próprio DML, a ponto de as imagens, odores e contato manual não os impactarem com a mesma intensidade ao longo do tempo. Evidencia-se, ainda, que trabalhar em contato com a morte demanda dos necrotomistas elaborações subjetivas que revelam uma capacidade de se transformar a partir de um fim perene, inflexível e trágico, ampliando as significações no tocante à vida.

A agenda de pesquisa aponta para os limites do que este artigo não pôde desenvolver. Chamou a atenção dos pesquisadores um discurso unânime, entre os participantes, referente ao fato de que, entre antigos necrotomistas, prevalecia com bastante frequência o consumo de álcool. Alguns relatos sugerem que mais da metade daqueles profissionais bebia exageradamente, apresentando-se, repetidas vezes, com hálito etílico ou embriagados nos horários de trabalho. No atual quadro, esse tipo de comportamento não foi relatado como uma característica da categoria, presente em apenas um profissional. Os necrotomistas aparentemente têm se mantido afastados da drogadicção. Por quê? Quais fatores têm concorrido para a quase ausência desse comportamento? Apesar de identificadas tais questões, os dados foram insuficientes para permitir, neste estudo, um 
aprofundamento. Entende-se, contudo, que tais questionamentos podem constituir temáticas a serem mais bem exploradas em pesquisas futuras.

Na perspectiva de estudos posteriores, sugere-se analisar a diferença entre lidar com a morte na área da saúde e na área pericial, do ponto de vista dos sentimentos emergidos e da resistência psíquica gerada. De acordo com Cavedon (2009), na área da saúde, a morte está presente após a realização da atividade. É consequência, complicação ou fracasso. Na área pericial, é a morte que antecede a atividade. É ela o dispositivo que sinaliza o início das atividades de necrotomistas e peritos. Tais características, seja do trabalho dos necrotonomistas, seja da organização à qual se vinculam, devem favorecer a construção de políticas organizacionais adaptadas que atendam aos requisitos de um trabalho com qualidade.

Ressalta-se, por fim, que a pretensão da presente pesquisa é apresentar contribuição de caráter social, uma vez que descortina o trabalho pouco (re)conhecido dos necrotomistas, profissionais que, apesar de invisíveis no laudo final, são figuras centrais em todo processo de necropsia e, por conseguinte, importantes para o desenrolar de cadeias investigativojudiciais.

\section{Referências}

Aldé, L. (2003). Ossos do ofício: processo de trabalho saúde sob a ótica dos funcionários do Instituto Médico-Legal do Rio de Janeiro [Dissertação de Mestrado, Fundação Oswaldo Cruz]. ARCA Repositório Institucional da Fiocruz. https://www.arca.fiocruz.br/handle/icict/5233

Almeida, F. A. (2005). Lidando com a morte e o luto por meio do brincar: a criança com câncer no hospital. Boletim de Psicologia, 55(123), 149-167. http://pepsic.bvsalud.org/pdf/bolpsi/v55n123/v55n123a03.pdf

Avellar, L. Z., Iglesias, A., \& Valverde, P. F. (2007). Sofrimento psíquico em trabalhadores de enfermagem de uma unidade de oncologia. Psicologia em Estudo, 12(3), 475-481. https://doi.org/10.1590/S1413-73722007000300004 
Barros, V. A., \& Silva, L. R. (2004). Trabalho e cotidiano no Instituto Médico Legal de, Belo Horizonte. Psicologia em Revista, 10(16), 318-333. https://doi.org/10.5752/P.1678$9563.2004 \mathrm{v} 10 \mathrm{n} 16 \mathrm{p} 318-333$

Bendassolli, P. F., \& Da Rocha Falcão, J. T. (2013). Psicologia social do trabalho sujo: revendo conceitos e pensando em possibilidades teóricas para a agenda da psicologia nos contextos de trabalho. Universitas Psychologica, 12(4), 1153-1166. https:// doi.org/10.11144/Javeriana.UPSY12-4

Butler, N., Chillas, S., \& Muhr, S. L. (2012). Professions at the margins. Ephemera: theory \& $\begin{array}{llll}\text { politics in } \quad \text { organization, 259-272. } & \text { 12(3), }\end{array}$ http://www.ephemerajournal.org/sites/default/files/12-3editorial.pdf

Cavedon, N. (2009). "Isso aqui é uma fábrica de loucos": a saúde mental dos servidores do departamento de criminalística do Instituto-Geral de Perícias do Rio Grande do Sul. Anais do XXXIII Encontro da ANPAD (pp. 1-16). São Paulo: Universidade de São Paulo. http://www.anpad.org.br/diversos/down_zips/45/GPR463.pdf

Cavedon, B. Z., \& Amador, F. S. (2012). Quando a morte é o começo da atividade: análise do trabalho pericial sob o ponto de vista da clínica da atividade. Barbarói, 37(1), 177-202. http://online.unisc.br/seer/index.php/barbaroi/article/viewFile/2459/2362

Costa, D. H., Njaine, K, \& Schenker, M. (2017). Repercussions of homicide on victims' families: a literature review. Ciência \& Saúde Coletiva, 22(9), 3087-3097. https://doi.org/10.1590/1413-81232017229.18132016

Cru, D. (1987). Les règles du métier. In C. Dejours (Ed.), Plaisir et souffrance dans le travail (tomo 1, pp. 29-42). Paris: AOCIP/CNRS.

Dejours, C. (1988). Souffrance et plaisir au travail, l'approche par la psychopathologie du travail. In C. Dejours, Plaisir et souffrance dans le travail (pp. 12-28). Paris: Edition de I'AOCIP.

Dejours, C. (1994). Entre souffrance et réappropriation. Les sens du travail. Le Nouveau Politis, La Revue, 433-468.

Dejours, C. (2001). Subjectivité, travail et action. La Pensée, 328, 7-19.

Dejours, C. (2009). Travail vivant. Paris: Petit Biblio Payot.

Dejours, C. (2012). Trabalho vivo (F. Soudant, Trad.). Brasília: Paralelo 15. 
Dejours, C. (2013). A sublimação - entre sofrimento e prazer no trabalho. Revista Portuguesa de Psicanálise, 33(2), 9-28.

Dejours, C. (2014a). Le facteur humain (6a ed.). Paris: PUF.

Dejours, C. (2014b). Souffrance en France: La banalisation de l'injustice sociale. Montrouge: Points.

Dejours, C. (2015a). Le choix, Souffrir au travail n'est pas une fatalité. Paris: Bayard.

Dejours, C. (2015b). Travail, usure mentale: Essai de psychopathologie du travail. Montrouge: Bayard (édition augmenté).

Dejours, C. (2016a). Commentaire. In C. Dejours, Situations du travail (pp. 33-37). Paris: PUF.

Dejours, C. (2016b). Activisme professionnel : masochisme, compulsivite ou aliénation? In C. Dejours, Situations du travail (pp. 239-256). Paris: PUF.

Dejours, C. (2016c). La résistence. In C. Dejours, Situations du travail (pp. 287-300). Paris: PUF.

Dejours, C. \& Gernet, I. (2012). Psychopathologie du travail. Issy-les-Moulineaux, Paris: Editeur Elsevier Mason.

Emerson, R. M., \& Pollner, M. (1976). Dirty work designations: Their features and consequences in a psychiatric setting. Social Problems, 23(3), 243-254. https: / / doi.org/10.2307/799771

França, G. V. (2011). Medicina Legal (9a ed.). Rio de Janeiro: Guanabara Koogan.

Gernet, I. (2009). Les relations entre santé et travail du point de vue de la psychodynamique du travail. Mouvements, 58(2), 79-84. https://doi.org/10.3917/mouv.058.0079

Halpern, E. E., Ferreira, S. M. B., \& Silva Filho, J. F. (2008). Os efeitos das situações de trabalho na construção do alcoolismo de pacientes militares da marinha do Brasil. Cadernos de Psicologia Social do Trabalho, 17(2), 273-286. http:/ /www.revistas.usp.br/cpst/article/viewFile/25785/27518

Hughes, E. C. (1962). Good People and Dirty Work. Social Problems, 10(1), 3-11. http:// www.jstor.org/discover/10.2307/799402?uid=3737664\&uid=2\&uid=4\&sid=21 1 02142762513 
Kessler, I., Heron, P., \& Dopson, S. (2012). Opening the window: managing death in the workplace. $\quad$ Human 291-312. https:// doi.org/10.1177/0018726711430002

Laville, C., \& Dionne, J. (1997). La construction des savoirs: manuel de methodologie en sciences. Montreal: Cheneliere/McGraw-Hill.

Lhuillier, D. (2013) Introduction à la psychosociologie du travail. Nouvelle revue de psychosociologie, (15), 11-30.

Lima, M. E. A. (2010). Dependência química e trabalho: uso funcional e disfuncional de drogas nos contextos laborais. Revista Brasileira de Saúde Ocupacional, 35(122), 260268. http://doi.org/10.1590/S0303-76572010000200008

Mattos, M. J. S. (2012). Reconhecimento, identidade e trabalho sujo na PMDF [Dissertação de Mestrado, Universidade de Brasília]. Repositório Institucional da Universidade de Brasília. http://repositorio.unb.br/bitstream/10482/1 1 166/4/2012_MarcioJuliodaSilvaMattos.pd $f$

Messias, J. S. (2017). Estudo clínico da atividade laboral dos técnicos em necropsia de um serviço de verificação de óbito do Nordeste do Brasil [Dissertação de Mestrado, Universidade Federal do Rio Grande do Norte]. Repositório Institucional UFRN. https: / / repositorio.ufrn.br/jspui/bitstream/123456789/25273/1/JoederDaSilvaMessias _DISSERT.pdf

Molinier, P. (2008). Les enjeux psychiques du travail. Introduction à la psychodynamique du travail. Paris: Petit Biblio Payot.

Oliveira, P. R., Schirmbeck, T. M. E., \& Lunardi, R. R. (2013). Vivências de uma equipe de enfermagem com a morte de uma criança indígena hospitalizada. Texto \& Contexto Enfermagem, 22(4), 1072-80. https://doi.org/10.1590/S0104-07072013000400025

Oliveira, N. (2015, 30 de novembro). Mortes violentas crescem 3,8 pontos percentuais em $\begin{array}{llll}\text { quatro } & \text { décadas. } & \text { Agência }\end{array}$ http://agenciabrasil.ebc.com.br/geral/noticia/2015-11/mortes-violentas-crescem-38pontos-percentuais-em-quatro-decadas

Prestes Jr, L. C., \& Ancilotti, R. (2009). Manual de técnicas em necropsia médico-legal. Rio de Janeiro: Editora Rubio. 
Scarton, J., Poli, G., Kolankiewicz, A., Rosanelli, C. L., Scarton, J., \& Poli, A. (2013). Enfermagem: a morte e o morrer em unidade de terapia intensiva pediátrica e neonatal. Revista de Enfermagem UFPE on line, $7(10), \quad 5929-5937$. https:// doi.org/10.5205/reuol.4377-36619-1-ED.0710201313

Seligmann-Silva, E. (201 1). Trabalho e desgaste mental. O direito de ser dono de si mesmo. São Paulo: Cortez.

Silva, F. L. L. (2014). Análise da atividade de trabalho dos necrotomistas [Dissertação de Mestrado, Universidade Federal da Paraíba]. Repositório Institucional da UFPB. https://repositorio.ufpb.br/jspui/handle/tede/6972

Silva, F. L. L., Zambroni-de-Souza, P. C., \& Araújo, A. J. S. (2014). Análise das condições e da organização do trabalho dos necrotomistas. Psicologia em Estudo, 19(1), 81-91. https://doi.org/10.1590/1413-7372213280008

Silva, F. L. L., Souza, P. C. Z., Araújo, A. J. S., \& Pinto, F. M. (2016). Estigmatização e Riscos no Trabalho dos Necrotomistas. Psicologia: Teoria e Pesquisa, 32(1), 133-141. https://doi.org/10.1590/0102-37722016012302133141

Silva, L. C., Valença, C. M., \& Germano, R. M. (2010). Estudo fenomenológico sobre a vivência da morte em uma unidade de terapia intensiva neonatal. Revista Brasileira de Enfermagem, 63(5), 770-774. https://doi.org/10.1590/S0034-71672010000500012

Souza, K. C. C., \& Boemer, M. R. (1998). O significado do trabalho em funerárias sob a perspectiva do trabalhador. Saúde e Sociedade, 7(1), 27-52. https: / / doi.org/10.1590/S0104-12901998000100003

Wisner, A. (1984). L'anthropotechnologie, outil ou leurre? Technologies, Idéologies, Pratiques, (5), 28-59. http://laboreal.up.pt/fr/articles/a-antropotecnologiaferramenta-ou-engodo/

Zambroni-de-Souza, P. C., \& Athayde, M. (2006). A contribuição da abordagem clínica de Louis Le Guillant para o desenvolvimento da Psicologia do Trabalho. Estudos e Pesquisas em Psicologia, 6(1), 6-19. http://pepsic.bvsalud.org/pdf/epp/v6n1/v6n1 a02.pdf 